\title{
La gestión cultural' de la educación artística desde las artes escénicas²se inicia en el emplazamiento de procesos de formación que devienen de los maestros de las artes escénicas en la escuela básica y media
}

\author{
Artistic education cultural management \\ based on performing arts begins when positioning training processes, which are \\ proposed by teachers of performing arts in basic and secondary school
}

Carolina Merchán Price*

\section{Resumen}

La relación entre la enseñanza del teatro en la escuela y los procesos de aprendizaje y desarrollo de los niños constituye un campo de investigación central en la educación artística. En este texto se abordan las posibles extensiones que, desde la inclusión de las artes escénicas como disciplina escolar, se abren en los niveles macro, meso y micro que inciden en la gestión de una institución. En el primer nivel, se aborda el tema desde la perspectiva de la gestión cultural y las políticas públicas que regulan el devenir escolar y las relaciones fuera de la escuela. En el nivel meso, se alude a la necesidad de cambiar la mirada de los formadores en relación con el arte como objeto cultural y su incidencia intrainstitucional. En el nivel micro, se presenta la validación de la "cultura de grupo" que viabiliza la construcción del sujeto como ser de convivencia, y como sujeto en construcción cognitiva, axiológica y social. En las conclusiones se propone una discusión de estas diferentes pistas que actualmente orientan las investigaciones en este campo.

\section{Palabras clave}

Escuela, artes escénicas, gestión cultural, procesos de formación, formadores.

\section{Abstract}

The relationship between theater teaching at school and the learning process and child development is a priority area in research in art education. This text will deal with several aspects that due to the inclusion of performing arts as a part of teaching (K-12 level school) open to three levels: macro, meso and micro, which influence the management of the institution. At a macro level, the question is addressed from the perspective of cultural management and public school policy and the dialectic between the school community and its social and cultural environment. At a meso level, the issue will be the need to change teachers/trainers conceptions concerning the relationships between art as cultural objects and its incidence inside the school. At a micro level, the focus will be the positive impact of the "group culture" as a tool for subject construction in many areas: social, axiological and cognitive. A discussion of different clues that guide current research in art/theater education will be proposed in the conclusions.

\section{Keywords}

School, performing arts, cultural management, training processes, teachers.

Artículo recibido el 11 de septiembre de 2008 y aprobado el 14 de noviembre de 2008.

* Profesora de planta del programa de Licenciatura en Artes Escénicas de la Facultad de Bellas Artes de la Universidad Pedagógica Nacional. Profesional en Estudios Literarios de la Universidad Javeriana. Actualmente Coordinadora del programa de Licenciatura en Artes Escénicas de la Universidad Pedagógica Nacional

Correo electrónico: carolamerchan@yahoo.com

1 La gestión cultural y la formación de gestores se entiende como escenario que pone en juego intereses diversos acerca de la posesión, circulación y consumo de bienes culturales; son también territorios de conflicto donde tienen lugar luchas sociales por la hegemonía cultural y donde los distintos sectores sociales rivalizan por la apropiación y creación de productos culturales. Como territorios de contienda 


\section{Introducción}

Forma parte del emplazamiento de la educación artística ${ }^{3}$, específicamente de las artes escénicas en la escuela, determinar puntualmente qué de las disciplinas que componen las artes escénicas es transferible a la escuela como eje de formación y, en lo que supone esta indagación, sus implicaciones para la educación en el desplazamiento del objeto artes escénicas.

Uno de los obstáculos que todavía deja brumas en los enunciados de las artes en la escuela tiene que ver con el hecho de que la mayoría de los maestros de prácticas artísticas en las licenciaturas en artes en las universidades, y aún en las escuelas, son sobre todo artistas, y los profesores que imparten las cátedras sobre educación y pedagogía son licenciados no artistas. Esta especialización en los saberes que determinan la formación de formadores en el caso de la educación superior y el no conocimiento del arte por parte de los licenciados en educación trae consigo dificultades a la hora de articular los vínculos posibles entre arte y pedagogía.

social, la gestión cultural y la formación de gestores son también espacios donde se ponen en funcionamiento estrategias discursivas que hacen posible la valoración de ciertos productos culturales sobre otros y donde se tejen y circulan formas de apropiación cultural y subjetividad. Bustos, M. (2000). Formación en gestión cultural. Bogotá: Dirección de Etnocultura y Fomento-Ministerio de Cultura, pp.11-12.

2 Artes escénicas: están ligadas a la presentación, ligadas a la representación directa -no diferida o recibida a través de un medio de comunicación- del producto artístico. El equivalente inglés, performing arts, traduce adecuadamente la idea fundamental de estas artes escénicas. Son "conformadas", creadas directamente, hic et nunc, para un público que asiste; (a) la representación: el teatro hablado, cantado, bailado o mimado (gestual), la danza, la pantomima y la ópera son los ejemplos más conocidos. No tiene ninguna importancia la forma del escenario, ni la relación escenario-sala (relación teatral); lo que cuenta es la inmediatez de la comunicación al público mediante los perfomance (actores, bailarines, cantantes, mimos, etc.). Pavis, P. (2003). Diccionario de teatro. Taurus.

3 La educación artística, entendida como la educación mediante el arte y dirigida a la formación de sujetos, involucra tres ejes disciplinares o tres dominios: la producción o creación, la apreciación y la comprensión sociocultural de la misma. Cualquiera de los tres encarna lo que puede llamarse conocimiento artístico, fruto de procesos, estrategias y recursos cognitivos cuyas particularidades obedecen a la naturaleza misma del campo de conocimiento, en tanto sistema simbólico distinto al lógico matemático o narrativo lingüístico fuertemente afincados en la escuela. En cualquier caso, posibilidades aprensibles y educables. (Aguirre, 2002; Efland, 2004 y Eisner, 1995).
Solamente desde hace pocos años ha cobrado importancia la educación artística para ser desarrollada en la escuela, más allá del desarrollo de talentos, como articulador de saberes, como propiciador de ambientes de aprendizaje transformadores, motivadores, distintos.

\section{Algunos antecedentes desde las políticas públicas}

En la historia de Colombia han existido tres leyes generales de educación que corresponden a las políticas educativas para la educación formal; en las dos primeras, Decreto Orgánico de Instrucción Pública (1870-1903) y Ley Orgánica de Educación (1903-1994), se consideraron algunas disciplinas artísticas como parte del currículo; sin embargo, la educación teatral no tuvo cabida en éstas. Con la nueva Constitución Política de Colombia, que se establece en 1991, se da un giro a la regulación de la educación nacional. Se instaura, así, la tercera Ley General de Educación o Ley 115 de 19944, de la que se derivan dos políticas educativas para las diferentes disciplinas del área artística, éstas son: Los Indicadores de Logro de 1996 y Los Lineamientos Curriculares Para la Educación Artística del año 2000, en las que finalmente se tiene en cuenta por primera vez la educación teatral en las políticas educativas del país 5 .

Atendiendo a lo dicho y habida cuenta de que las políticas educativas son las directrices que deben seguir los establecimientos en sus PEI, es importante articular los procesos de formación artística en el área y su consecuente traslación al espacio escénico pedagógico ${ }^{6}$. Se impone así la necesidad de iniciar

4 En ella se define la educación como un proceso de formación permanente personal, cultural y social que se fundamenta en una concepción integral de la persona humana, de su dignidad, de sus derechos y de sus deberes. Ley General de Educación 115/94, la cual señala las normas generales para regular el servicio público de la educación, se fundamenta en los principios de la Constitución Política de Colombia sobre el derecho a la educación que tiene toda persona, en las libertades de enseñanza, aprendizaje, investigación y cátedra y en su carácter de servicio público.

5 Tomado de Gloria Lorena Díaz. (2007). Análisis documental del estado de la educación teatral en las políticas educativas de Colombia, 1994-2006. FBA, UPN.

6 Espacio escénico pedagógico corresponde al espacio sugerido donde se desarrollen los procesos propios del teatro como disciplina de formación de sujetos en la escuela. Un espacio escénico 
trabajos de investigación y práctica a través de los cuales se defina cómo los procesos propios del área se transforman en herramientas pedagógicas para la formación de sujetos integrales, humanos, reflexivos, y aportar en ellos espacios pertinentes desde las artes y sus particularidades.

Los planes de desarrollo regionales han determinado la obligatoriedad de la educación artística para todos en la escuela básica y media. Pero la obligatoriedad no basta la obligatoriedad. Se hizo necesario implementar programas de licenciaturas universitarias específicas desde las artes que formen profesores en estas disciplinas. Es así que en las diferentes facultades de distintas universidades del país se han abierto programas de licenciatura en artes ${ }^{7}$ que desarrollan su currículo en las dos disciplinas fundantes, la pedagogía y las artes. Sin embargo, estos esfuerzos aún no son suficientes. Para el mejor emplazamiento de la educación artística en la escuela, es función de los programas universitarios determinar las justas diferencias entre la formación de artistas y la formación de sujetos por medio del arte, así como los dispositivos que desde estas diferencias deben articular los programas. $\mathrm{Y}$ es que, aunque los programas de licenciatura en artes se han ido fundamentando poco a poco, aún es asunto de discusión el desplazamiento de los saberes particulares del arte hacia asuntos de mediación en la escuela como objetos culturales formativos, así como en la comprensión, asimilación y transformación de la herencia cultural.

Por tanto, es del interés y fuero de la Licenciatura de Artes Escénicas de la Universidad Pedagógica Nacional, con siete años de trayectoria, delimitar los niveles y procesos de gestión cultural que inciden en la formación de sujetos. Y en lo particular del arte, definir los procesos específicos que forman al actor

privado, extensible e infinito tiene una función específica en la escuela: formar en el conocimiento y en la convivencia; hacer teatro escolar es dotar a los alumnos de un espacio privilegiado para la construcción de su identidad, para el desarrollo de sus capacidades como personas determinados en aprendizajes específicos: corporales, expresivos, interactivos.

7 Universidad Pedagógica Nacional, Universidad Distrital Francisco José de Caldas, Universidad de Caldas, Universidad de Antioquia, Universidad del Valle, entre otras. para desplazar los saberes y extender su sentido a la formación integral de sujetos en la educación básica y media. La pregunta principal para este artículo está centrada en identificar aquellos procesos de la formación de actores que son transferibles a la educación en artes escénicas en la escuela básica y media, toda vez que el espacio escénico se desplaza desde las prácticas artísticas hacia el espacio pedagógico, considerado entonces como espacio escénico pedagógico. Es finalmente en este último en el que pueden confluir los saberes propios del arte, sus extensiones en la construcción social y su funcionalidad en la formación de sujetos: desde su individualidad y como ser social perteneciente a un grupo, con necesidades formativas específicas, en contextos particulares, con intereses diversos más allá del gusto artístico o el talento.

La problemática que se aborda surge del hecho de que el marco teórico que rige la formación disciplinar en artes escénicas deviene de los teóricos e investigadores del teatro en sus preocupaciones específicas por el desarrollo del talento, el trabajo corporal como instrumento del actor, la dramaturgia como fuente esencial del producto estético y la interpretación en sus múltiples acepciones. Cuando estos saberes son desplazados al ámbito escolar, esta operación supone transposiciones y transformaciones de orden formativo social, determinación de procesos específicos en el campo, extensión de las motivaciones por la comprensión del arte y la cultura. Una reflexión sobre esta necesaria adaptación de los saberes al proyecto educativo es fundamental para la consecuente gestión del emplazamiento de la educación artística desde las artes escénicas en la escuela.

En este documento se pretende, entonces, explorar esta problemática a partir de un intento de articulación de algunos de los conceptos del maestro Eugenio Barba (1986), mediante los cuales viabilizamos la articulación de la cultura de grupo teatral con la consolidación de grupos escolares en los aprendizajes conjuntos de construcción de sujetos desde una visión del arte, la creación, la comprensión y la producción del teatro como ejes fundantes y la gestión escolar. Se asume como gestión escolar las 
extensiones que el trabajo en esta disciplina ${ }^{8}$ aporta a la escuela como lugar de encuentros, de formación y sus implicaciones en los niveles macro, meso y micro que se explican más adelante.

\section{Metodología. Desde las experiencias del artista a las experiencias de formación escolar}

El presente es un estudio de carácter descriptivointerpretativo y documental enmarcado en el paradigma hermenéutico. Se parte del texto Más allá de las islas flotantes de Eugenio Barba (1986), quien ha desarrollado modelos de formación teatral a partir de trabajos de laboratorio con actores y directores de teatro. Tiene en cuenta las reflexiones sobre el papel del público en las creaciones que propone, pero que, llevadas al espacio de la escuela, pueden plantearse como posibles dispositivos didácticos para la integración de saberes desde las particularidades de las artes escénicas en la formación de sujetos. Barba crea lo que llamó antropología teatral9: el estudio del comportamiento del hombre a nivel biológico y sociocultural en una situación de representación ${ }^{10}$. Trabaja por lograr un actor con amplia autoconciencia, despojado de juicios, máscaras, cotidianidad; constante en su entrenamiento, activando -en ensayos, improvisaciones y en el escenario- su cerebro, sistema nervioso y columna vertebral; indaga para que su voz sea una prolongación de su cuerpo y no dos cuerpos diferentes; $y$, sobre todo, se centra en la convicción de que el actor encontrará su ritmo -sus

8 Siendo del interés de la Licenciatura en Artes Escénicas avanzar en este tema desde los distintos maestros de las artes escénicas, se están realizando investigaciones de este mismo orden articuladas a los desarrollos específicos desde las Inteligencias Múltiples de Gardner con los maestros Stanislavsky y Grotowsky, pilares de la formación de actores desde inicios del siglo XX.

9 La antropología teatral no busca principios universalmente verdaderos, sino indicaciones útiles. No tiene la humildad de una ciencia, sino la ambición de individualizar los conocimientos útiles para el trabajo del actor. No quiere descubrir "leyes", sino estudiar reglas de comportamiento. (Barba, 1986: 198).

10 Utilizamos nuestro cuerpo de manera sustancialmente diferente en la vida cotidiana y en las situaciones de "representación". A nivel cotidiano, tenemos una técnica del cuerpo determinada por nuestra cultura, nuestra condición social, nuestro oficio. Pero en una situación de "representación" existe una utilización del cuerpo, una técnica del cuerpo, que es totalmente distinta. Se puede, pues, distinguir una técnica cotidiana de una técnica extra-cotidiana. propias pulsaciones tan particulares que hacen único, propio y particular su desarrollo actoral- para iniciar su desarrollo como individuo en un grupo a la vez que se forma en él.

Este mismo proceso tiene ecos en los espectadores, en los actores, en esa comunidad cerrada que a veces se abre para mostrar los trabajos. Trabajos que, al ser mostrados, se abren a nutrir y ser nutridos con relaciones cercanas, casi íntimas, que a su vez crecen y se transforman. Crea y evidencia la necesidad del encuentro con el teatro de parte del público. Y, para nosotros, abre exclusas para pensar, desde la escuela, el sentido de las artes escénicas como mediadoras de formación en el crecimiento de los individuos, los grupos y las instituciones.

El teatro es una práctica artística que es, ante todo, una práctica social. Preguntarse por las relaciones entre teatro y escuela, desde el campo de la gestión cultural, se justifica a varios niveles que el siguiente trabajo intentará desarrollar:

En primer lugar, a nivel macro (relaciones entre la escuela como institución social y la sociedad, en particular las colectividades que se desarrollan en torno a la escuela): la necesidad de articular la escuela como institución social (sus modos de funcionamiento y sus valores) con el teatro como una de las prácticas sociales que, históricamente, interrogan a las instituciones y los valores de la sociedad. En efecto, desde los trabajos sociológicos de Bourdieu y Passeron (2003), pero igualmente desde los principios de la pedagogía crítica de Paulo Freire (1970), se viene trabajando una idea de escuela como vector de cambio social mediante el desarrollo de los individuos como ciudadanos. En este sentido, el teatro aparece como una práctica social que ofrece múltiples claves de lectura para la construcción de una visión crítica y reconstructora de las instituciones, funcionamientos, símbolos y valores de los grupos sociales.

Todos los comportamientos humanos -y aún sus más íntimas fantasías- han estado y estarán contenidos siempre en el teatro. A partir de esta concepción de mimesis, sólo hay que alterar el orden alfabético, lingüístico, gestual, semiótico o emocional, establecido (Barba, 1986: 11). 
Integrar procesos propios del quehacer teatral en la cotidianidad escolar propende al conocimiento empírico, en la acción y organización de cada uno de estos órdenes; de conocer los códigos de comunicación en sus diferentes niveles para explicarse, para comprenderlos y apropiárselos, en tanto se comprendan, o buscar transformaciones de los mismos en cuanto generen una cultura que posibilite cambios para el desarrollo de los grupos de escolares (no necesariamente de teatro).

En segundo lugar, a nivel meso (relaciones intra-escuela, pero a nivel institucional). Son numerosos los etnólogos y sociólogos que han recurrido a la metáfora teatral para describir y explicar el funcionamiento de los grupos sociales (Goffman, 1974; Dubar, 2000; Lahire, 2001); los proyectos de montaje teatral y de espectáculos no solamente tienen eventualmente incidencia en la colectividad inmediata de la escuela (padres de familia, centros de acción comunal, barrio, etc.), sino que también pueden conllevar cambios en la institución escolar misma. Estos cambios implican las relaciones entre los diferentes estamentos que tienen que colaborar y cooperar para llevar a cabo un proyecto de envergadura (dirección, coordinadores pedagógicos, docentes y alumnos); implican igualmente modos de lectura de la institución y de su funcionamiento que pueden traer incidencias positivas. Por ejemplo, forman parte de los trabajos de investigación actualmente en desarrollo en la Universidad Pedagógica Nacional una serie de investigaciones directamente relacionadas con el quehacer de los docentes (manejo de la voz, manejo de la proxemia y del espacio del aula como espacio dramatúrgico, manejo de las posturas y de las interacciones sociales, etc.) que muestran los aportes que el teatro, como práctica sociocultural, puede instalar en la institución. Como en la historia de la ciencia, también en la historia del arte y del teatro, lo esencial se esconde bajo el desarrollo del método, bajo los intentos pedagógicos y la transmisión del saber. La palabra armonía11

11 La armonía es acuerdo entre tensiones. Si siento la falta de algo esencial para mí, el acuerdo dentro de mí no es perfecto. Es como si un fragmento de vacío estuviera ahí, en mí, y quisiera llenarlo y para hacerlo me viera obligado a ponerme en marcha. Este estar indica el sentido de esta lucha personal en busca de nuevas tensiones que recreen la vida, que imprima un renovado sentido a aquello que perdió y está perdiendo sentido. No nuevos hechos, sino nuevas relaciones entre hechos (Barba,1986:24) Y que más allá del deseo de toda una comunidad haciendo teatro quedan en el intersticio de las comunidades las posibles reflexiones sobre aquello que "naturalmente" se acepta, pero que, al desnaturalizarlo y hacerlo consciente y "distante" en los ejercicios dramáticos, se hacen manifiesto, invitando a la reflexión del sentido de los códigos y maneras que las se manejan en las instituciones; $y$, sin duda, al exterior cercano con las familias que son otra de las instancias en las cuales se generan las acciones y los códigos de comportamiento social.

En tercer lugar, a nivel micro (relaciones pedagógicas en el aula). Este es el nivel más importante por cuanto fundamenta a todos los demás. Por esta razón, le otorgamos un mayor espacio en este texto. Barba insiste en la consolidación de un grupo dedicado al teatro a partir de las diferencias culturales, en el que las líneas de trabajo tienen como resultado diversidad en lo técnico y lo estético. De su concepción de entrenamiento de grupo dice: “[...] Las relaciones que rigen la existencia del grupo no comprometen solamente el trabajo, sino también la vida entera de los miembros" (Barba, 1986: 24). Y en el aula, cada uno de los miembros es un niño o una niña, jóvenes con historia de vida y proyectos de futuro, que están ahí para construir procesos de individuación y competencias para la convivencia y que, en la producción específica de obras de teatro y sus múltiples procesos y conformaciones, se construyen, además, en lo colectivo y sus responsabilidades sociales (Alcaldía Mayor de Bogotá, 2007):

El actor, para recibir lo transmitido por el director, debe ser valorado como un individuo motivado por sus propios intereses y búsquedas [...], debe tener su conciencia alerta para absorber lo esencial y llegar a la escena a hacer partícipes a los espectadores de sus experiencias, comunes a

de viaje, para encontrar cómo aplacar el vacío, revela el sentido de lo que me empuja y me nutre (Barba,1986: 24). 
las de la humanidad, es decir, la manifestación y la búsqueda de la vida; por esta razón esta labor merece respeto.

Pero no basta tener la conciencia alerta: es necesario construir la mirada del profesor para validar y consolidar las experiencias de los alumnos, desde la implementación de didácticas específicas que le den herramientas a los profesores para orientar relaciones en el aula, formas de ver el mundo, para reconsiderar situaciones específicas, relaciones. Los ejercicios que se desarrollan en el entrenamiento escénico - así como las improvisaciones dramáticas y situaciones de representación desde lo ficcional y el "si mágico"-, se constituyen en herramientas provocadoras de ser implementadas e investigadas como formadoras en conciencia de sí mismo, sentido del "otro" y comprensión del mundo.

En otras palabras: en el marco de este texto se aborda una mirada muy particular sobre el término "gestión cultural", a partir del ejemplo concreto de la implementación de las prácticas teatrales en la escuela y de las reflexiones que este tipo de proyecto implica en el campo pedagógico, en el del desarrollo de sujetos y en el del desarrollo social. Gestión cultural puede entonces leerse, en este escrito, como la gestión de un tipo de proyecto particular: el montaje de espectáculos escolares y el trabajo desde y sobre el teatro en el aula, que tiene incidencias a niveles macro, meso y micro y que, por tanto, amerita una reflexión no solamente pedagógica o meramente artística, sino en términos de acción social (gestión).

\section{A nivel Macro: la necesidad de implementar actividades desde el teatro para potenciar la dimensión mediacional de la institución educativa}

La función social del teatro ha determinado su largo camino de transformación en el transcurso de la historia. Desde la Grecia antigua, con la tragedia y la comedia, está ya sugerida la función que puede llegar a desempeñar el arte escénico en una cultura: mantener una tradición, abordar los misterios de la condición humana, mostrar los males que pueden corroer una sociedad y aportar en la resignificación de sentidos y la creación de posibilidades (Rodríguez Adrados, 1997). La educación busca revaluar modelos caducos que han permitido avances significativos en el desarrollo del individuo, pero que ahora deben potenciar sus energías hacia la constitución de competencias que permitan a los sujetos: el reconocimiento propio y del otro, del trabajo y la disciplina personal y en grupo; comprender a la mayor cantidad de individuos posible, aún en las fragmentaciones a las que la actualidad ha llevado a las comunidades.

En este sentido, consideramos que la educación por medio de las artes escénicas puede representar un interesante avance en la construcción de sociedad, toda vez que construye su particularidad desde el individuo hacia el grupo y viceversa, a la vez que con el público. Pero aún no se han definido temas específicos que permitan dilucidar puntualmente cómo y qué de la configuración artes escénicas genera desarrollo en el sujeto y transformación en el entorno. Por tanto, también es del fuero de los investigadores de la educación artística desentrañar articulaciones pedagógicas específicas para ampliar el marco de la gestión cultural en cuanto se inicia ésta en la construcción de sujetos como sabedores de su propia cultura; ampliar el sentido de las artes en ella y determinar competencias y capacidades particulares viables de ser desarrolladas como un eje de construcción nocional.

Estas opciones hacen eco a concepciones más comunicacionales de la escuela y de lo pedagógico (Habermas, 1981) en el ámbito social. Se sabe que desde el inicio de la escuela obligatoria, a finales del siglo XIX en Europa, la institución escolar ha estado sometida en permanencia a dos tensiones que la han ido configurando en las formas institucionales que la recorren durante el siglo XX. Por una parte, la escuela técnica-profesional, cuya versión actual corresponde a las tendencias de trabajar los currículos en términos de competencias, tiene como objetivo central preparar obreros de diferente nivel técnico y profesional para el mercado laboral. Por otra parte, la escuela humanista (Decroly, Dewey, Claparède) hace sus aportes centrada más en el desarrollo de la persona y del futuro ciudadano. Ninguna de las dos tendencias ha sido representada de manera absoluta, salvo contadas excepciones, en 
las formas que ha tomado históricamente la escuela tradicional obligatoria. Más que concepciones formales, podemos aquí hablar de tendencias que marcan las decisiones curriculares, los métodos pedagógicos privilegiados, las formas de evaluación utilizadas, etc. El campo de la enseñanza artística ha sido particularmente marcado por las tensiones entre estas dos concepciones -como lo señalan Mili y Rickenmann, 2005 y Thévenin, 1992- que pueden ser resueltas desde los ámbitos actuales a partir de la noción de formación integral.

La idea de una formación teatral como instrumento de gestión cultural a nivel macro (es decir, de las instituciones sociales) parte de las posibles articulaciones que se pueden establecer desde:

a. La idea actual de la mediación cultural como herramienta de desarrollo (Bronckart, 1980, Bruner, 2000 y Not, 1983) que privilegie a la vez la participación activa del sujeto en sus procesos de aprendizaje y reconozca el papel estructurante de la escuela como contexto de desarrollo.

b. La evolución del teatro mismo, en especial desde el teatro pedagógico brechtiano y hasta el teatro implicado de Eugenio Barba, como práctica de crítica y autoconcieciación social.

En lo que respecta al primer punto, las constataciones hechas a partir de la perspectiva histórico-cultural (Vigotsky, 2001 muestran, en efecto, que para el ámbito escolar es legítimo hablar de enseñanza, noción que implica un proyecto consciente y formalizado de transmisión de las claves o herramientas que producen las significaciones de la realidad material y humana.

Las obras humanas emergen en ámbitos histórico-sociales, como respuestas específicas de la colectividad a los cuestionamientos de la realidad. Las obras y las prácticas sociales que a ellas conciernen (crear, comunicar, exponer, criticar, analizar, interpretar, conservar...) constituyen cristalizaciones de la experiencia humana (Meyerson, 1987), Mediante cuyos usos sociales la colectividad transmite las herramientas culturales para conocer, comprender, crear o transformar, a la vez, los mundos y los individuos que los habitan. En este sentido, hacer entrar el teatro en la escuela significa potenciar claves de lectura de las situaciones y eventos histórico-sociales que esta forma de arte cristaliza y "traduce" en sus formas y lenguajes. La articulación se da, justamente, en lo que respecta al segundo punto: por las características particulares que ha tomado el teatro durante el siglo XX en lo concerniente a su papel social, cultural e histórico.

Baste con recordar la dimensión pedagógica del teatro brechtiano, que está orientada hacia la crítica, la concientización social sobre las formas -colectivas e individuales- que toma la acción humana en nuestras sociedades. Por un lado, la producción de obras invita a determinadas reflexiones en cuanto a lo que sucede en las familias, los grupos de amigos, la comunidad. Por otro, lleva conflictos sociales a otras épocas para leerlos desde la distancia, a la vez que propone juegos desde la misma actuación, para estimular la imaginación y desde ella la comprensión del mundo.

Cabe hacerse preguntas sustantivas con respecto a qué valores sociales estamos transitando, y si no es el escenario pedagógico un lugar privilegiado para el estudio y conocimiento de una sociedad, para develar los valores que se manifiestan o son posibles de ser manifestados en el espacio escénico pedagógico. Este escenario pedagógico propone lugares de discusión y debate en los entornos cercanos a las comunidades educativas convocando a quienes las sustentan. "Las obras de arte son también fuentes de grandes revelaciones acerca de la cultura local, la cultura de los otros y otros tiempos históricos" (Efland, 2004); dan cuenta, con el paso del tiempo, de avances en el "manejo de materiales", cambios de mentalidad, comprensión histórica desde el ahora, resignificando la comprensión del mundo, poniendo estos avances al servicio de las siguientes generaciones. Construyen así, además, nuevas formas de expresión que permean la sociedad y reflejan a su vez lo social de su tiempo (Habermas, 1981); "Salpican", en este sentido, la actualidad de otras maneras de ver el mundo, de comprenderlo y asimilarlo al tiempo que enriquece la comprensión del ser, permitiendo la re-actualización tanto de "aquellos" signos y significaciones que devienen de la historia como de 
la comprensión de la propia realidad y los "signos" cercanos. Permite la opción de las conversaciones culturales mediante el arte, al tiempo que instala opciones de ver y rehacer el mundo del sujeto, del entorno, de la realidad.

¿Cuál es el papel de la escuela en estas movilizaciones, en su comprensión, en su participación? El teatro como manifestación cultural; la sala de teatro como lugar de esa manifestación cultural y lo que allí sucede, es, existe y pervive en tanto actores, directores, y un público definido se moviliza en su interior. Ahora se abre como un "otro" lugar- aula o aula-teatro para la comprensión de esos mundos posibles que se hacen visibles mediante sus obras, sus ejercicios.

El espacio escénico popular, las ferias, los mercados, se presenta como lo que podríamos llamar hoy "espacios de representación no convencionales" donde los juglares, acróbatas y actores de comedias hacen gala de sus esfuerzos en el teatro callejero. Es también lugar de indagaciones el teatro como entretenimiento, importantísimo en cualquier sociedad, pero ¿qué clase de entretenimiento produce? ¿Cuál es su potencial en la vida de a pie -en un mundo que pareciera hacer oda permanente a los medios masivos de comunicación, de entretenimiento satelital masivo pero solitario-, si por el contrario invita a las comunidades a convocarse en la calle, en los parques? Preguntas que se desprenden e incitan a plantear trabajos de investigación para entender las necesidades culturales de las comunidades y que, en su momento, buscan espacio en la escuela: ¿Cuál es la incidencia de estas vertientes en la vida cultural de una ciudad? ¿De una localidad? ¿De un pueblo? ¿De un barrio? ¿Qué clase de obras se presentan y por qué? Y llegaríamos sin duda a otro de los puntos que se plantean más adelante: la formación de públicos y el sentido de esta formación tanto para el individuo como para la comunidad misma.

El espacio público es un lugar de construcción de la sociedad y sus valores (Haberma, 1981). ¿Cuáles son las relaciones entre el teatro y la esfera pública? ¿Cómo funcionan, se instalan y se crean mundos comunes y qué dimensiones axiológicas inscriben?

\section{El nivel meso: un cambio de mirada desde las necesidades pedagógicas del ejercicio teatral en la escuela}

Con respecto a una obra de teatro, un artista director de teatro, crítico, dramaturgo o actor fijará su mirada en la experticia de los actores en la apropiación y creación de los personajes; analizará la articulación entre los mismos de acuerdo con la propuesta de la obra escrita, si es de un autor reconocido o de una escuela teatral; de la profundidad del trato de la fábula y cohesión del grupo, si es una propuesta nueva centrando sus criterios en elementos propios de la crítica teatral. Por el contrario, un profesor de teatro escolar deberá centrar sus criterios de educación y de evaluación no en la puesta en escena, en el espectáculo (aunque los logros en ella y los fracasos en la representación influirán en su papel como profesor, mediador); será de hecho tema de discusión en torno a los saberes específicos del teatro y material significativo para su quehacer. Pero su evaluación estará determinada por los enunciados que comprometen el quehacer y el saber ser de los niños y jóvenes en el proceso mismo de montaje. $Y$ mediante éste, también evaluará su propio proceder en cuanto a definición de instrucciones, proceso de implementación, recursos escénicos desplazados hacia las edades con las que estará trabajando. Los criterios de evaluación del docente formador estarán dirigidos desde las características particulares del teatro que puedan potenciar los procesos formativos de los alumnos, toda vez que en la vinculación arte y pedagogía logre puntualizar el para qué de su acción docente y el qué de la transformación que se busca a nivel formativo, cognitivo, actitudinal y cultural de los grupos (no solamente de teatro vocacional) a su cargo.

Por tanto, la obra, ya sea espectáculo, texto, ejercicio de creación, se desplaza de "producto" a "medio"; generador de procesos de aprendizaje tanto cognitivos como actitudinales y cuyos objetivos están en vías aún de determinarse de acuerdo con las expectativas de la extensión del teatro como herramienta pedagógica. La "transmisión" de saberes es del orden de la co-construcción de la realidad 
humana y de los individuos. En este sentido, las artes escénicas se presentan, desde la idea de la pedagogía como espacio escénico, en un lugar para las experiencias, que permite dar sentido a los diversos aprendizajes de-en la escuela. El mundo de la educación escolar constituye una de las principales fuentes de estas maneras de hacer y de pensar. Su especificidad exige un tratamiento disciplinario, un conocimiento de los diversos objetos de saber y de la manera en que funcionan tanto a nivel pragmático como a nivel de su interiorización psicológica. "En el más allá del teatro estaba el 'trueque': el intercambio de nuestra presencia teatral" -entrenamiento, espectáculos, experiencias pedagógicas con las actividades de otros grupos teatrales o con grupos de espectadores (Barba, 1986: 20).

Mediante las artes escénicas el aula se abre. El quehacer en su interior se expone, pero a este nivel, se abre además a un lugar "cerrado", la misma escuela, los otros grupos, los otros niveles. Y al mostrarse genera movimientos en su interior, que se inician en las búsquedas y asombros de los individuos, en sus grupos cercanos, en el más allá de las escaleras y los pasillos. Desde el inicio de las secuencias didácticas, uno de los procesos permanentes que se realizan en el quehacer formativo del teatro es que se reflexiona. Se conversa desde espacios de confianza en lo que sucede cada día en los ejercicios, ya sean dirigidos a montaje, o sencillamente como parte del "entrenamiento".

$\mathrm{Al}$ ser mostrado hacia el exterior revelaba la red de nuestras relaciones internas, aquello que nos defendía frente a los demás, no como actores de un espectáculo, sino como un pequeño grupo de hombres que tienen una historia y una común actitud (Barba, 1986: 19).

La necesidad permanente de reflexión viene con la acción de participación en las dinámicas propias del quehacer teatral. La educación como cosa de todos, como cultura común, se construye en la medida en que no solamente los profesores formadores desde esta disciplina afinan sus habilidades gestoras, sino que en el emplazamiento del teatro, como materia para todos, los colegas profesores y la administración necesariamente forman parte de los movimientos que desde el interior de los niños se inician en el aula.

Los espacios de confianza se construyen, y con ellos los lugares para ser y estar con los “otros", en la experiencia de articular saberes, mundo vivido, expectativas individuales y grupales. Los espacios de confianza habilitan competencias de convivencia, desde mirarse y mirar alrededor; desde la comprensión de los signos y símbolos culturales y sociales que atraviesan tanto el interior como el exterior escolar. Esas relaciones se construyen desde el saber y la acción cotidiana en los espacios de formación. Abrirlos, determinarlos y construirlos en función de la gestión social que aquí se propone es parte de las proyecciones y el sentido de las artes escénicas en la escuela y la comunidad como extensión. "Todo depende de la experiencia. Y la experiencia está basada en la cantidad de errores que uno haya cometido" (Barba, 1986: 67).

\section{Nivel micro: el teatro como medio de desarrollo de las capacidades cognitivas, cinestésicas, corporales, emotivas...}

La educación artística:

Presupone que el desarrollo de capacidades e intereses artísticos es una parte más del aprendizaje; la cognición, que no está limitada a los más dotados para las artes. Este aprendizaje permite que los individuos construyan significados culturales que permitan la comunicación social, la objetivación y apropiación del material simbólico de la cultura y el desarrollo de capacidades expresivas ligadas a la construcción como individuos pertenecientes a una sociedad (Efland, 2004 y Vigotsky, 2001).

La educación artística implica, además, el desarrollo de habilidades y competencias que construyan planos artísticos, planos críticos, planos de elaboración y reproducción desde y para la expresión en el sujeto. Forma procesos y lenguajes que aportan a la decodificación del mundo y sus relaciones, a la vez que contribuyen a las capacidades de expresión. Permite la emergencia de registros afinados en la comprensión de los otros al tiempo que la comprensión de las relaciones con los otros amplía y desarrolla las 
opciones de construcción de sí mismo. No en vano Vigotsky plantea la conciencia como un diálogo interior con uno mismo (2001). En la escuela, el arte como "constructo" toma otra perspectiva: la del arte como vehículo de construcción grupal y personal.

Cultura de grupo: Eugenio Barba12 trabaja durante años "encerrado" con su grupo, en retiro. Y mediante sus investigaciones de formación teatral y de grupo establece ciertos conceptos desde los cuales queremos partir para proponer esta posible trasposición de procesos formativos del actor a los procesos de formación del sujeto en la escuela.

El "secreto 13" que habíamos buscado, tan sólo para garantizarnos las mejores condiciones para el desarrollo profesional, había producido un resultado imprevisto: el coagular de una verdadera y propia "cultura de grupo".

La escuela es en sí misma un lugar cerrado donde confluyen alumnos de diferentes edades y se distribuyen por grupos de edades pares, a quienes se les asigna un programa específico particular. Asisten a clases en aulas, también cerradas, pero con la intención primordial desde la escuela, sus rectores y profesores de que en cada una de las aulas los alumnos se formen, socialicen, se desarrollen. Por tanto, los alumnos están sujetos a pertenecer a un grupo, en el cual año tras año consolidan una cultura propia. La pregunta que emerge aquí, es ¿cómo el saber desde el teatro, desde la "cultura de grupo" de Barba aporta a la consolidación de la "cultura de grupo" escolar? Y ¿cómo aportar desde los conocimientos de Barba a la implementación y conocimiento desde el formador a esta "cultura de grupo"? Dice Barba que "el grupo tiene un saber y experiencias en común, entrenamiento, visiones artísticas y objetivos

12 Barba consolida un grupo de teatro fuera de su país de origen, en Dinamarca, y sus compañeros de trabajo van llegando de distintos países y ciudades. Cada uno habla un idioma diferente, viene de una escuela teatral diferente, tiene en sí una cultura propia. A partir de un trabajo minucioso, comprometido consolidarán poco a poco su "Odin teatret".

13 (Barba, 1986: 20) Nuestras dos salas de trabajo, en Holstebro, eran los ambientes separados ("secretos", en sentido etimológico) en los que la búsqueda del actor podía desarrollarse protegida de los disturbios externos, en una situación de mutua confianza, sin estar sometida a la tiranía de los juicios prematuros y del afán de producirla. Las actividades con las cuales éramos visibles al exterior. propios" (Barba, 1986: 20). Y sobre todo que trabaja en una situación de "mutua confianza sin la presión de la tiranía de juicios prematuros”. Este sentido también incluye el lugar del "lugar secreto", desde donde en la generación de confianza los actores/ ahora alumnos escolares, tienen la libertad necesaria de ensayar, de buscar, de ir cada día más allá de ese gesto, de esa respuesta, de esa proposición a través de la cual exploran sus opciones. Este "lugar secreto" para los grupos en exploración de entrenamiento corporal, gestual, actitudinal y de reflexión supone un espacio potencial de generación de conciencia social, relacional y de construcción tanto individual como colectiva. "Se trata de tener confianza, de contar con el compañero". Es una metáfora que en el intento de traducirla al ámbito escolar, y más específicamente a los posibles ambientes de aprendizaje, promete, con la cooperación de los profesores, lugares de crecimiento y reconocimiento. Con todo lo que ello puede significar, desde lo particular y propio de cada uno de los integrantes. El saber al que se refiere Barba compromete a cada uno de los participantes en el trabajo que se propone.

Este saber se corresponde al mood propio de cada grupo, a partir justamente de cada uno de los individuos que lo conforman, su lugar en el grupo, su ser particular, su construcción y de lo que de él aporta al grupo en la consolidación de experiencias en común. Con entrenamiento, extendemos el sentido a los procesos de concienciación que desde los "juegos" teatrales despiertan en el "actor", ahora sujeto en formación: conciencia de su cuerpo, de su actuar, de sus sistemas de relación que en el aula como espacio escénico le permite reconocer, explorar. Los ejercicios dramáticos separados entre sí determinan en el entrenamiento del arte dramático la posibilidad de rehacer los gestos que se han ido asimilando y construyendo durante la infancia en el accionar social, pero que desde el entrenamiento en la escuela suponen la posibilidad de ajustarse a las expectativas en el escenario del personaje, en la vida social, en la búsqueda de la individualidad, la confianza en sí mismo, de las relaciones. Términos como "espontaneidad, corporalidad, exploración de 
la propia flora vocal14, estados de alerta, sí ficcional, movimientos extra-cotidianos, ritmo"15 abren el telón al desarrollo de los alumnos desde elementos particulares escénicos que, a la vez, vinculan las relaciones entre mente y cuerpo. Éstos soportan implicaciones cognitivas de flexibilización curricular, (Efland, 2004) de conocer y desarrollar competencias sociales, culturales; competencias que es necesario potenciar y que están en vías de definición; pero que alimentan la necesidad en los alumnos de encontrar sus propias palabras para expresar y decir de sí en el tránsito de su construcción.

Un segundo elemento tiene que ver con el funcionamiento particular de las situaciones formales de enseñanza-aprendizaje. La enseñanza es transmisión de significados; es decir, está sometida al juego de la comunicación, en el que no hay solamente emisores todopoderosos, sino receptores activos que interpretan los signos que se producen y transforman en el contexto. En el acto de enseñar no solamente se transmite, por decirlo así, "el código"; también y, sobre todo, se transmiten las "reglas de uso" (en el sentido de Wittgenstein). Es decir, las herramientas que permiten hacerlo funcionar o transformarlo. Es por esta última razón que la enseñanza no puede limitarse a una aproximación de la educación en términos de objetivos y habilidades generales y descontextualizadas. Por el contrario, los conocimientos y habilidades adquieren sentido solamente cuando están encarnados en objetos e integrados a contextos en los que "funcionan": En otras palabras, cuando se dan en el ámbito de la experiencia (Dewey, 1958). Vemos cómo, de esta manera, la implementación de proyectos teatrales

14 La voz, como proceso fisiológico, compromete todo el organismo y lo proyecta en el espacio. La voz es una prolongación de nuestro cuerpo. Nos da la posibilidad de intervenir de un modo concreto, incluso a distancia. Como una mano invisible, la voz se extiende más allá de nuestro cuerpo y actúa, y todo nuestro cuerpo vive y participa en esta acción. El cuerpo es la parte visible de la voz y puede verse dónde y cómo nace el impulso que se convertirá en sonido y palabra. La voz es cuerpo invisible que obra en el espacio. No existe separación ni dualidad: voz y cuerpo. Existen solamente acciones y reacciones que comprometen a nuestro organismo en su totalidad.

15 (Barba, 1986). Cada uno de estos conceptos son desarrollados por los actores del Odín, desde las particularidades de cada uno, pero gestando criterios comunes. en la escuela puede constituir un espacio en el que se contextualicen experiencias y aprendizajes básicos en comunicación y expresión.

"Si queremos comprender el mundo social humano tenemos que recurrir a las artes que forman parte de ese mundo" (Efland, 2004 y Goodman, 1995). Esa comprensión del mundo desde ese lugar tiene un matiz que vale la pena reconocer como particular: se corresponde a otro plano de conocimiento, que no es el único plano de conocimiento del mundo, sino uno de otros y, en este sentido, reconocerlo como uno de entre otros facilita abrir las exclusas que así lo permitan. Supone posibles integraciones desde otras disciplinas que le aportarán a este conocimiento que se reconoce como una más. Entonces, este conocimiento le aportará a los otros, y extendiendo este espacio se hace posible pensar en la proyección de objetivos propios, metas en los proyectos comunes, retos de diversa índole que motiven y movilicen desde y hacia realidades sociales, escolares, artísticas, académicas.

En lo que respecta a visiones artísticas, tenemos en principio la educación artística, entendida como la educación por medio del arte dirigida a la formación de sujetos e involucra tres ejes disciplinares o tres dominios ${ }^{16}$ : la producción o creación, la apreciación y la comprensión sociocultural de la misma ${ }^{17}$. Cualquiera de los tres encarna lo que puede llamarse conocimiento artístico fruto de procesos, estrategias y recursos cognitivos cuyas particularidades obedecen a la naturaleza misma del campo de conocimiento, en tanto sistema simbólico distinto al lógico matemático o narrativo lingüístico (Aguirre, 2002) fuertemente afincados en la escuela. En cualquier caso posibilidades aprensibles y educables.

La educación teatral aborda elementos importantes que integran el desarrollo de capacidades cognitivas, físicas y axiológicas, particulares a

16 Eisner, Efland o Aguirre, aunque nombrándolos de maneras distintas, básicamente coinciden en los tres dominios y Aguirre plantea cuatro áreas: Historia, Crítica, práctica taller y estética. Cabe mencionar sin embargo que la inclinación de la escuela tal como lo señalan los autores ha estado dirigida solamente a la creación de obras..

17 Las comprensiones sobre cada eje se encuentran descritas en los referentes conceptuales. 
cada individuo, que contribuyen en su formación integral, en especial en el ámbito de la resolución de problemas y la imaginación. El teatro coadyuva en procesos de interrogación del sujeto acerca de sí mismo y de los otros, de reflexionar constantemente sobre sus actividades, de imaginar, asignar sentido a textos, visualizar y crear "partituras físicas" y caracterizaciones emotivas de personajes en el orden de lo vivido (Habermas, 1981). En la medida en que activa procesos individuales, moldea las interacciones con los otros en una complementación recíproca, simultánea, que extiende sus significaciones desde el individuo hacia el grupo y viceversa. Influye en las reacciones, los estados de atención y las opciones de interacciones a la vez que vincula la toma de decisiones desde procesos específicos que resuelven "problemas" en las situaciones que se realizan.

Se piensa, con frecuencia, que un grupo de teatro tiene una unidad... si sus "integrantes se asemejan"; al contrario es necesario buscar la diferenciación recíproca, si se quiere conseguir la totalidad (Efland, 2004: 207)..

La asimilación y construcción de personas desde estas diferencias son competencias que construye el formador en su interés de aportar a cada uno de sus alumnos. El aula es también el lugar de construcción de las relaciones entre los alumnos y el profesor: por tanto, es el lugar de construcción del profesor, quien a su vez necesita herramientas y apoyos que le permitan ejercer su papel como mediador.

Por otra parte, la imaginación, vista desde la educación teatral, desempeña un papel importante en la creación de significado personal: como menciona Efland (2004: 207):

Sólo en las artes los procesos y los productos de la imaginación se encuentran y exploran con plena conciencia; se convierten en objetos de investigación. $\mathrm{Y}$ es este aspecto el que otorga nuevas percepciones y visiones, lo que aviva el pensamiento.

En este orden de ideas, el trabajo que se realiza en la educación teatral en busca de intensificar la imaginación pone en evidencia lo que constituye a cada ser humano en sus particularidades. El hecho de crear un personaje, de concebir un espacio, de estructurar en la mente imágenes, tiempos, objetos que no están, o de resignificarlos, requiere de actos creativos e imaginativos. Pero sobre todo obligan a la comprensión de los referentes primeros, originales tanto a nivel textual como a la comprensión de las situaciones planteadas en los ejercicios en los que se interactúa para formar parte del juego escénico. Tenemos pues que es necesario que el alumno no solamente lea y comprenda, imagine, sino que además debe llevar su pensamiento (lo comprendido y lo ficcionado) a acciones físicas concretas, en un espacio y un tiempo determinado; en esta medida, la imaginación abordada desde la educación teatral trasciende el campo de la mente para entrar en relación con el cuerpo, y de éste con el espacio, con los otros, haciéndose componente del escenario de formación.

Entonces, el sujeto se enfrenta a la necesidad de resolver problemas consigo mismo y con los otros. Debe enfrentar las diferentes situaciones a las que se ve expuesto en la disciplina, como la construcción de un personaje, el manejo del espacio, la relación con los demás, entre otras; se enfrenta a dificultades $y$ posibilidades que tiene para resolver conflictos $y$, a la vez, desarrollar actos creativos, actos de creación. En esta medida, se genera en él un estado de incertidumbre en el que debe poner a prueba su capacidad para construir sus propias interpretaciones y a la vez su capacidad para reconocer y trabajar en las situaciones que se le proponen como provocaciones tanto físicas como mentales, individuales y grupales. Se convierte en parte del desarrollo de conocimiento personal a partir de la confrontación, las contradicciones y las contrariedades. Y todo esto en un espacio abierto para probarse, para relatarse, para construirse consigo mismo y con los otros. Barba expone un término que prefigura un trabajo profundo en la configuración de las competencias del docente con la disposición para el trabajo y el crecimiento de los niños en relación con los procesos de las disciplinas de las artes escénicas: la espontaneidad ${ }^{18}$, que a la vez tiene entre sus definiciones la

18 En la raíz del término "espontaneidad" se encuentra implícito el concepto de libre elección. El problema de la espontaneidad concierne tanto a la libertad como a la seguridad: la libertad de escoger frente a distintas alternativas sin ser obligados a una elección impuesta 
capacidad del niño de conocerse en sus límites lo suficiente para poder actuar. Es decir, supone un conocimiento de sí mismo, reflexivo y que desde sus propias indagaciones le da seguridad y libertad en sus interacciones.

\section{Discusiones. Hacia el afincamiento de criterios en el espacio escénico pedagógico}

Mediante las pistas exploradas en este texto se han podido puntualizar algunos aportes que puede dar la educación teatral en la escuela en los tres niveles de acción: macro, meso y micro. Pero la literatura consultada, tanto desde la pedagogía como desde el teatro, ha permitido ir más allá. Se ha podido constatar la manera en que el trabajo a nivel micro, en el aula de clase con el grupo escolar y los sujetos que lo conforman, implica ya de hecho relaciones estrechas con los otros dos niveles. A partir de los planteamientos de Vigotsky, se ve que el aporte cultural del teatro para la construcción de individuos es al mismo tiempo una construcción de sujetosmiembros de un grupo social y cultural. Por otra parte, las reflexiones propuestas por Barba sobre las dinámicas de trabajo de grupo actoral abren pistas sobre la manera en que pueden ser implementados este tipo de procesos y con qué efectos tanto en los sujetos como en la institución en la que se desenvuelven (la escuela como institución).

A nivel meso, desde los procesos de gestión cultural en los grupos de teatro, se regulan las necesidades en vías de convocar público para hacerlos formar parte de la representación y que sin su presencia invalida los esfuerzos en los grupos. Esta relación del grupo escolar con el público (los otros alumnos, los padres, el resto de la comunidad que rodea la escuela) forma parte de la necesaria construcción de sentido del quehacer teatral desde la escuela; recurrir a prácticas auténticas para dar sentido a los aprendizajes que se llevan a cabo en el

por el exterior; la seguridad de ser capaces de realizar lo que se ha escogido, sin tropezar con bloqueos materiales o psíquicos, sin encontrarse impedidos por una falta de conocimientos técnicos o por el medio; por ejemplo, de lo que los otros dirían de nosotros (Barba, 1986). aula forma parte, en efecto, de las actuales estrategias educativas. La dinámica de proyecto tiene la ventaja de confrontar a los alumnos a la realidad sociocultural del oficio (presentarse ante un público: sus pares, sus padres o la comunidad), lo que coadyuva a la construcción de sentido a los aprendizajes que propone el maestro.

La dinámica de proyecto conlleva igualmente beneficios potenciales en las relaciones intraescolar, siempre a nivel meso. Se hizo referencia a trabajos investigativos que se llevan a cabo actualmente desde la Licenciatura en Artes Escénicas, los cuales muestran aportes específicos del teatro para la práctica docente (manejo de voz, manejo del espacio, manejo de las relaciones humanas). Pero, si además se considera la riqueza de oficios relacionados con el teatro y con el montaje escénico, se verá la manera en que se abre una amplia paleta de posibles trabajos interdisciplinarios tanto al interior de la escuela (texto teatral y enseñanza de la lengua y la literatura; trabajo corporal y educación física y deportiva; montajes escénicos y artes plásticas, ebanistería, confección, etc.) como al exterior de la misma. También con la posibilidad de entrar en contacto con otros oficios presentes en la comunidad cercana.

Este punto permite articular lo anterior con el nivel macro. Esta gestión se inicia con el proyecto en el aula, ahora espacio escénico pedagógico. Desde el entrenamiento que supone la preparación del actor, ahora sujeto en formación, viabiliza a través de él y con la mediación de formadores capaces de afinar la mirada hacia y desde procesos específicos mediante las artes escénicas y la singularidad de saberes y construcciones que de ellas se desprenden. Pasa después a las incidencias que puede tener el proyecto en la escuela, a nivel meso. Termina con el sentido social y cultural de este tipo de trabajos esencialmente desde dos aspectos. El primero, ya subrayado, es el de la creación de públicos que perpetúen o renueven la vida artística de la comunidad y de la sociedad. Una gran mayoría de los niños que aprovechan una formación teatral en la escuela no serán ni pretenden ser nunca actores, desarrollar talentos específicos para el oficio. Sin embargo, esta mayoría será probablemente un público más experimentado, 
experto, sensible a la oferta cultural, crítico frente a su funcionamiento social. En esta medida, habrán sido preparados para ser no solamente individuos, sino sujetos miembros de una colectividad, con capacidad participativa y renovadora. El segundo, en parte implicado en el punto anterior, consiste en que más allá de los saberes culturales, la educación teatral aporta una formación integral a los sujetos, a la vez corporal, sensitiva, intelectual y espiritual; $y$ esto lo hace a partir del grupo como núcleo de individuación mediante el cual los alumnos aprenderán a ser parte de la sociedad en la que se desenvuelven, sin por ello sacrificar su propia subjetividad. Así, la presentación teatral desde la escuela para el público interno y externo potencia fenómenos colectivos de la mayor importancia: mejoramiento de la imagen de la escuela ante la comunidad, educación de un público en el respeto de las miradas y valores que se vehiculen por medio de las piezas presentadas $y$ del trabajo de los personajes y situaciones, integración y cohesión de la escuela y sus "actores" con la comunidad y sus "actores".

Se ve entonces la manera en que terminan integrándose los tres niveles: los valores y prácticas que el docente realiza con sus alumnos mediante los entrenamientos, los ejercicios, y las prácticas educativas ligadas al proyecto permean paralelamente o ulteriormente en los otros dos niveles. El estudio muestra, en este sentido, las problemáticas sobre las que tendrá que asentarse la investigación y práctica de la formación de formadores desde la universidad. Las determinaciones de procesos específicos en la formación de actores son múltiples, como lo son también las teorías en esta disciplina desde los maestros del teatro.

Pero, sobre todo, se visualiza que para el emplazamiento de esta disciplina en el espacio escolar de la educación básica y media es necesario el apoyo de cada uno de los estamentos que dirigen la escuela. Por un lado, las políticas públicas que se han abierto desde la Ley 115 de 1994, pero, principalmente, la dirección de voluntades desde la escuela misma, desde la reevaluación del PEI, en la contratación de licenciados en educación artística que egresan de las universidades y que portan en sus construcciones como docentes los saberes específicos tanto en lo pedagógico como en los disciplinar artístico.

Los avances en el desarrollo de modelos pedagógicos encaminados a la viabilidad de abrir espacios de reflexión en el aula, de ingenierías didácticas que apunten a la co-construcción de saberes, de, específicamente, pedagogías que inscriban la educación artística como eje de construcción de sujetos están a la orden del día. Asimismo, las investigaciones que parten de los enunciados de Vigotsky en torno a que la construcción del sujeto es del orden histórico-cultural y de investigadores más actuales como Efland, Aguirre, Barbosa, Read, Hargreaves, Arnheim, que desde sus categorizaciones en educación artística determinan ejes teóricos involucrando las necesidades de la formación integral desde el aula. También se abren espacios de investigación puntuales en los desarrollos posibles en la construcción de sujetos desde la propia educación artística en las prácticas pedagógicas, dilucidando los aportes que desde la música, las artes visuales (Mili y Rickenmann, 2005) y escenarios más amplios desde los formadores (Bronckart, 1980 y Sensevy, 2007) amplían los marcos conceptuales para la implementación de una educación artística para todos, como lo supone el interés de la escuela. \. 


\section{Referencias bibliográficas}

Aguirre, I. (2002). Teorías y prácticas de la educación artística. España: Octaedro.

Alcaldía Mayor de Bogotá. (2007). Rutas pedagógicas de la educación artística en Bogotá. Bogotá: Idep.

Barba, E. (1986). Más allá de las islas flotantes. México: Gaceta.

Bronckart, J. P. (1980). Teorías del lenguaje. Barcelona: Herde.

Bruner, J. (2000). La educación, puerta de la cultura. Madrid: Visor.

Bourdieu, P. y Passeron, J. (2003). Los herederos: los estudiantes y la cultura. Buenos Aires: Siglo XXI Editores.

Constitución Política de Colombia 1991.

Decreto 1002 de 1984.

Decreto 2343 de 1996.

Decreto 1860 del 3 de agosto de 1994.

Dewey (1958). Art as experience. Nueva York: Capricorn Books.

Dubar, C. (2000). La socialisation. Construction des identités sociales et professionnelles. París: Armand Colin.

Efland, A. (2004). Arte y cognición. La integración de las artes en el currículum. Barcelona: Octaedro.

Eisner, E. (1995). Educar la visión artística. Barcelona: Paidós Educador.

Freire, P. (1970). Pedagogía del oprimido. Montevideo: Tierra Nueva.

Freire, P. (1999). Pedagogía de la Autonomía. México: Siglo XXI Editores.

Goffman, E. (1973). La mise en scène de la vie quotidienne. París: Minuit.

Goffman, E. (1974). Les rites d'interaction. París: Minuit.

Goodman, N. (1995). Maneras de hacer mundos. Madrid: Visor.

Grotowski, J. (1970). Hacia un teatro pobre. España: Siglo XXI Editores.

Habermas, J. (1981). Teoría de la acción comunicativa. Madrid: Taurus.
Jauss, H. R. (1985). Teoría de la recepción. México: Fondo de Cultura Económica.

Jagger, W. (1949). Paideia. México: Fondo de Cultura Económica.

Lahire, B. (2004). El hombre plural, los resortes de la acción. Barcelona: Bellaterra.

Ley General de Educación 115 de 1994.

Meyerson (1987). Écrit 1920-1983. Pour une psychologie historique. París: Presses Universitaires de France.

Mili, I. y Rickenmann, R. (2005). Approches didactiques dans l'enseignement artistique: une revue de littérature sur la construction de l'expertise culturelle en classe. Revue Suisse des Sciences de l'éducation, 27(3).

Ministerio de Cultura. (2007). Educación artística y cultural, un propósito común. Documentos para la formulación de una política pública colombiana. Bogotá: Cuadernos de Educación Artística.

Ministerio de Educación Nacional. (2000). Lineamientos curriculares para la educación artística. Colombia: Cooperativa Editorial Magisterio.

Perrenoud, P. (2004). Diez nuevas competencias para enseñar. Barcelona: Editorial Graó.

Not, L. (1983). Las pedagogías del conocimiento. México: Fondo de Cultura Económica.

Rickenmann, R. (2005, septiembre). "Didactics in art education and appropriation of cultural objects in classroom". 1st Iscar Conference. Sevilla.

Rickenmann, R. (2006). La question de la réception culturelle dans les enseignements artistiques. MEI.

Rodríguez Adrados, F. (1997). Democracia y literatura en la Atenas Clásica. Madrid: Alianza.

Sensevy, G., Schubauer-Leoni, M. L., Mercier, A. (2007). Agir ensemble: Laction didactique conjointe du professeur et des élèves. Presses Universitaires de Rennes.

Thévenin, J. C. (1992). Enseigner l’art. Art et éducation.

Vigotsky, L. (2001). Pensamiento y lenguaje. Madrid: Antonio Machado Libros. 